\title{
Analysis of Impacting Factors on Runoff and Sediment Transport of Flood Event in Gushanchuan Watershed
}

\author{
Jin Shuangyan, Jiang Xinhui, Zhang Zhiheng \\ Hydrology Bureau of Yellow River Conservancy Commission, Zhengzhou, China, 450004
}

Keywords: flood; rainfall intensity; climate change; human activity; Gushanchuan

\begin{abstract}
The turning point of water and sand of natural period and human activity impacting period in Gushanchuan basin is the year 1979, which analyzed by method of orderly clustering and MWP test. The model is established using the data before 1979, and the impacting factors on runoff and sediment transport of flood event after 1979 are analyzed.
\end{abstract}

The hydrology model in the basin is the major approach for analyzing the changes of water and sand, and assessing the benefits of water-soil conservation. Over the years, domestic and foreign research institutions and scholars established runoff and sediment yielding models based on the period of day. In this paper, the model of rainfall-runoff and rainfall-sediment of flood event in Gushanchuan watershed is established, and the impacts of climate change and human activity on runoff and sediment transport of flood event after 1979 are analyzed.

\section{Selection of flood and precipitation}

Gushanchuan, the first-order tributary of the Yellow River, covers 1,272 $\mathrm{km}^{2}$, locates in the overloaded and coarse sediment region, and $99.7 \%$ of the watershed exists in the centralized source area of coarse sediment. The watershed is the frequent occurrence region of high sediment flood.

There are observed data from 1954 to 2010 in Gaoshiya, the control hydrology station of Gushanchuan. The flood peak over than average annual maximum discharge of $1350 \mathrm{~m}^{3} / \mathrm{s}$ is selected. The annual maximal flood discharge is chose in dry water year, if this value is lower than $1350 \mathrm{~m}^{3} / \mathrm{s}$, and the occurrence of each choosing flood should avoid yearly peach flood.

Only four rainfall stations exist in Gushanchuan watershed, and the building year is 1966, 1960, 1966 and 1953 respectively, thus the fifty one floods during 1967 to 2010 are chose. According to flood peak time and travel time, indicators of the flood and relevant precipitation are calculated.

\section{Analysis of the turning point of water and sand}

The variation of runoff and sediment transport of flood event in Gushanchuan is analyzed by method of orderly clustering and MWP test. Thereby, the initial turning point from which human activity has notable impacts to hydrological series is ascertained.

\subsection{Method of orderly clustering}

The orderly clustering method is used to estimate possible prominent turning point of hydrology series based on the time series [1]. Supposing the possible turning point of flood hydrology series is variable $\tau$, the deviation square sum before and after turning point and the total is the following:

$$
\begin{aligned}
& V_{\tau}=\sum_{t=1}^{\tau}\left(x_{t}-\bar{x}_{\tau}\right)^{2}, \quad V_{n-\tau}=\sum_{t=\tau+1}^{n}\left(x_{t}-\bar{x}_{n-\tau}\right)^{2} \\
& S_{n}(\tau)=V_{\tau}+V_{n-\tau}
\end{aligned}
$$

Where, $\bar{x}_{\tau}$ and $\bar{x}_{n-\tau}$ are the mean value before and after the turning point respectively. The optimal turning point is satisfied with the standard $S_{n}^{*}=\min _{1<\tau<n}\left\{S_{n}(\tau)\right\}$.

The deviation square sum of rainfall, runoff and sediment transport during flood event in Gushanchuan watershed in 1979 is the lowest value, shown in Fig. 1 Fig. 3.

\subsection{Mann-Whitney-Pettitt testing method}

Mann-Whitney-Pettitt testing method (MWP) is one kind of nonparametric statistics method [2]. The formula is as follows: 


$$
\begin{gathered}
U_{t}=\sum_{i=1}^{t} \sum_{j=t+1}^{T} \operatorname{sign}\left(X_{i}-X_{j}\right) \\
\operatorname{sign}\left(X_{i}-X_{j}\right)= \begin{cases}1 & X_{i}>X_{j} \\
0 & X_{i}=X_{j} \\
-1 & X_{i}<X_{j}\end{cases}
\end{gathered}
$$

The maximal absolute value of $U_{\mathrm{t}}$ is the possible turning point. The $U_{\mathrm{t}}$ of rainfall, runoff and sediment in flood event in Gushanchuan of the year 1979 is the first crest, shown in Fig. 4 Fig. 6.
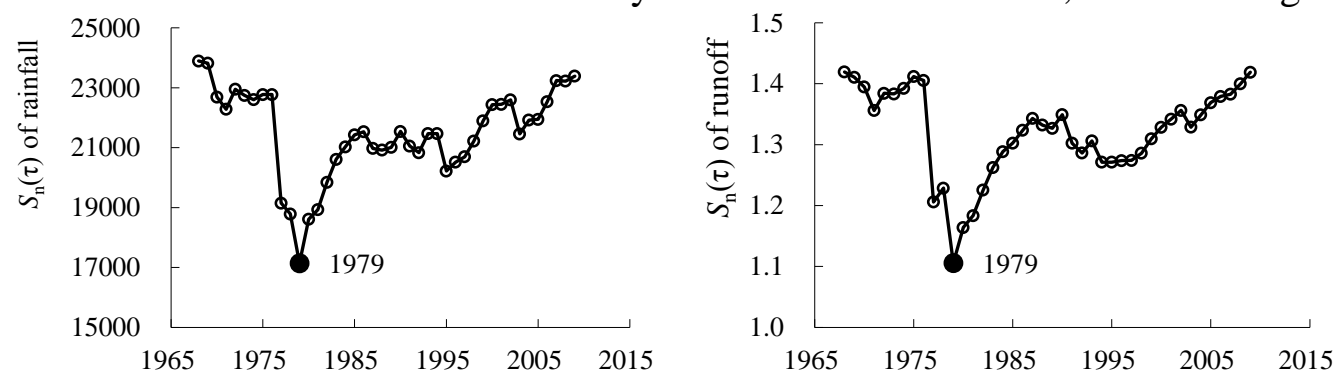

Fig. 1 The $S_{\mathrm{n}}(\tau)$ variety of rainfall in flood event
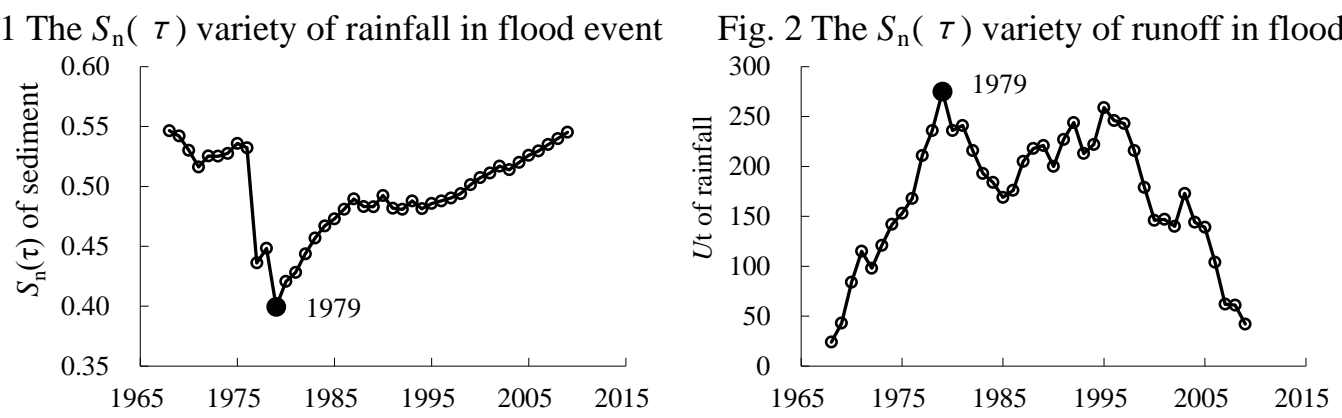

Fig. 3 The $S_{\mathrm{n}}(\tau)$ variety of sediment transport in flood
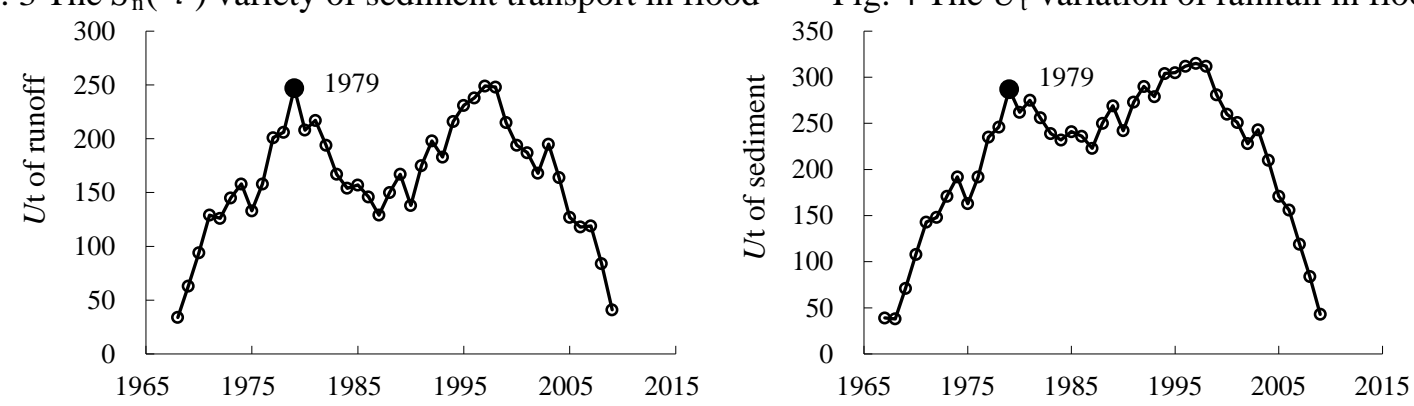

Fig. 5 The $U_{\mathrm{t}}$ variety of runoff in flood event Fig. 6 The $U_{\mathrm{t}}$ variety of sediment transport in flood

The method of rank sum test [3] is applied to verify the two separate samples, the number of which is 13 and 31. All the results of rainfall, runoff and sediment are showed as $|U|>u_{\alpha / 2}$, which displays the samples before and after turning point come from different distributing collectivity.

From the above statement, the year 1979 is the notable turning point of hydrological series during flood in Gushanchuan, and hydrological series earlier than 1979 is regarded as natural series.

\section{Model of rainfall-runoff and rainfall-sediment during flood}

Human activity and climate change should be regarded as two independent factors which impacted the variation of runoff and sediment transport in flood event, then to establish an appropriate hydrological model. Followed by the model parameters are calibrated by the observed data of precipitation and runoff based on natural condition, namely before the year 1979. Finally, the climate factors after 1979 are applied into hydrological model to analyze the impacts of climate change and human activity on runoff and sediment transport of flood event.

\subsection{Model establishment}

Owing to Gushanchuan watershed belongs to arid and semi-arid zone [4], high intensity rainstorm is the crucial reason of runoff yielding, the rainfall intensity should be considered when establishing the model. Here, firstly, plot the isoline diagram of rainfall in the basin and calculate mean areal rainfall. Afterward, establish the model between runoff\& sediment transport of flood 
event with the independent variable combined by the mean areal rainfall and rainfall intensity, shown in Fig. 7 and Fig. 8. The calibrating parameter is shown in Table 1.
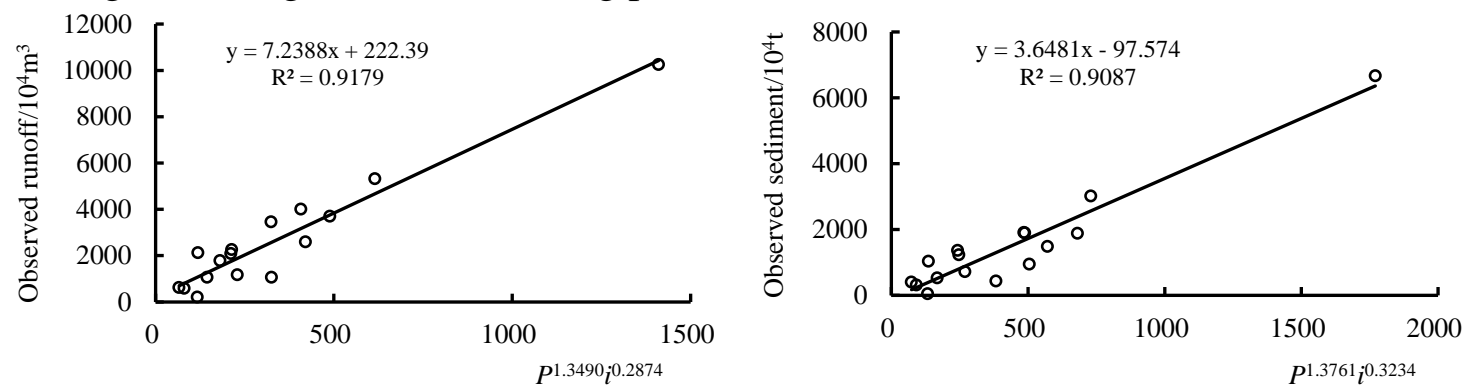

Fig. 7 Model of runoff and combined factor by $P$ and $i$

Fig. 8 Model of sediment and combined factor by $P$ and $i$

Table 1 Parameters of the model $\mathrm{P} \sim \mathrm{R}$ and model $\mathrm{P} \sim \mathrm{S}$ during flood in Gushanchuan

\begin{tabular}{|c|c|c|c|}
\hline Formula & $\alpha$ & $\beta$ & Relation coefficient \\
\hline$W=7.2388 x+222.39$ & 1.3490 & 0.2874 & 0.9581 \\
\hline$W_{S}=3.6481 x-97.574$ & 1.3761 & 0.3234 & 0.9533 \\
\hline
\end{tabular}

Where, $x$ is the variable $\left(\bar{p}^{a} i^{\beta}\right), W$ means runoff, $W_{S}$ shows sediment transportation.

The relationship between observed and simulated value of runoff and sediment transport of flood event in the watershed is illustrated in Fig. 9 and Fig. 10.
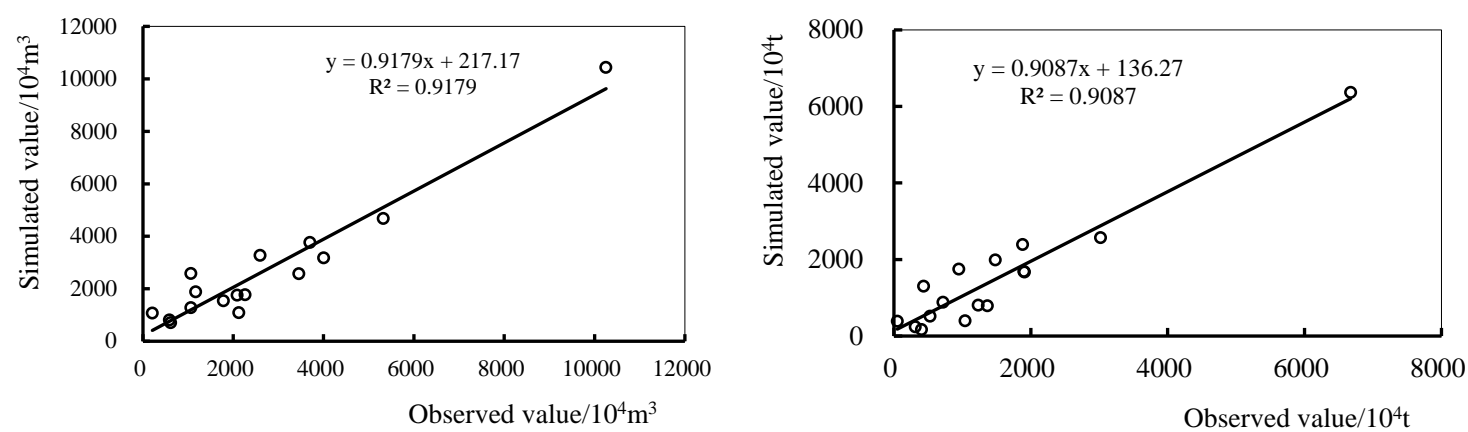

Fig. 9 Relationship between observed and simulated runoff Fig. 10 Relationship between observed and simulated sediment

3.2 Method of separate the impacts of climate change \& human activity to total flood runoff

The delta between observed hydrological indicators in the period of human activity and natural period data include two parts, namely the impacts of human activity and climate change [5].

$$
\begin{aligned}
& \Delta W_{T}=W_{2}-W_{1} \\
& \Delta W_{H}=W_{2}-W_{3} \\
& \Delta W_{C}=W_{3}-W_{1}
\end{aligned}
$$

Where, $\Delta W_{T}$, the changing total flood runoff ; $\Delta W_{H}$, the varying flood runoff impacted by human activity; $\Delta W_{C}$, the changing flood runoff impacted by climate change; $W_{1}$, the total flood runoff in natural period; $W_{2}$, the observed total flood runoff in the period of human activity; $W_{3}$, the natural total flood runoff in the period of human activity.

\subsection{Impacts of total flood runoff and sediment by climate change and human activity}

Using the model and above-mentioned formula, and according to the observed and computational value in different decades of Gushanchuan to analyze the impacts of climate change and human

\begin{tabular}{|c|c|c|c|c|c|c|c|c|c|}
\hline \multirow{2}{*}{ Time period } & \multirow{2}{*}{$\begin{array}{c}\text { Observed } \\
\text { value } \\
110^{4} \mathrm{~m}^{3} \\
\end{array}$} & \multirow{2}{*}{$\begin{array}{l}\text { Simulated } \\
\text { value } \\
/ 10^{4} \mathrm{~m}^{3} \\
\end{array}$} & \multirow{2}{*}{$\begin{array}{c}\text { Total } \\
\text { decrement } \\
/ 10^{4} \mathrm{~m}^{3} \\
\end{array}$} & \multicolumn{2}{|c|}{ Climate factor } & \multicolumn{2}{|c|}{ Human factor } & \multirow{2}{*}{$\begin{array}{c}\text { Total flood } \\
\text { precipitation } \\
/ \mathrm{mm}\end{array}$} & \multirow{2}{*}{$\begin{array}{c}\text { Peak } \\
\text { discharge } \\
/ \mathrm{m}^{3} / \mathrm{s} \\
\end{array}$} \\
\hline & & & & $10^{4} \mathrm{~m}^{3}$ & $\%$ & $10^{4} \mathrm{~m}^{3}$ & $\%$ & & \\
\hline 1967 1979 & 2645 & & & & & & & 53.3 & 2440 \\
\hline 1980 1989 & 895 & 942 & 1750 & 1703 & 97.3 & 47.0 & 2.7 & 22.0 & 1050 \\
\hline 1990 1999 & 1311 & 1852 & 1334 & 793 & 59.4 & 541 & 40.6 & 36.2 & 1200 \\
\hline $2000 \sim 2010$ & 455 & 1704 & 2189 & 941 & 43.0 & 1248 & 57.0 & 32.1 & 568 \\
\hline 1980 2010 & 874 & 1481 & 1771 & 1164 & 65.7 & 607 & 34.3 & 29.8 & 931 \\
\hline
\end{tabular}
activity on runoff and sediment transport of flood event. The result is shown in Table 2 and Table 3.

Table 2 Impacts of climate change and human activity on runoff of flood event in Gushanchuan

Table 3 Impacts of climate change and human activity on sediment transport of flood in Gushanchuan 


\begin{tabular}{|c|c|c|c|c|c|c|c|}
\hline \multirow{2}{*}{ Time period } & \multirow{2}{*}{$\begin{array}{c}\text { Observed } \\
\text { value } / 10^{4} t\end{array}$} & \multirow{2}{*}{$\begin{array}{l}\text { Simulated } \\
\text { value } / 10^{4} t\end{array}$} & \multirow{2}{*}{$\begin{array}{c}\text { Total } \\
\text { decrement } / 10^{4} \mathrm{t}\end{array}$} & \multicolumn{2}{|c|}{ Climate factor } & \multicolumn{2}{|c|}{ Human factor } \\
\hline & & & & $\left(10^{4} \mathrm{t}\right)$ & $(\%)$ & $\left(10^{4} \mathrm{t}\right)$ & (\%) \\
\hline 1967-1979 & 1493 & & & & & & \\
\hline 1980-1989 & 464.2 & 321.7 & 1029 & 1171 & 113.9 & -142.5 & -13.9 \\
\hline 1990-1999 & 474.0 & 883.9 & 1019 & 609.1 & 59.8 & 409.9 & 40.2 \\
\hline $2000-2010$ & 121.0 & 805.5 & 1372 & 687.6 & 50.1 & 684.5 & 49.9 \\
\hline 1980 2010 & 349.3 & 659.1 & 1144 & 834.0 & 72.9 & 309.9 & 27.1 \\
\hline
\end{tabular}

From the above statement, the following recognition can be got. The influencing extent by climate change and human activity on runoff and sediment transport of flood event in different period is dissimilar. The effect of climate factor to both runoff and sediment transport of flood event displays descending tendency. In 1980s, due to the distinct reduce of rainfall in flood event, the impact of climate factor on runoff and sediment transport of flood event is up to $97.3 \%$; although the sediment transport of flood event decreased $1029 \times 10^{4} t$ compared by the period before 1979 , this value decreased by climate factor reaches to $1171 \times 10^{4} t$ owing to the decreasing rainfall and silt brought by low peak discharge, and the result by human factor shows rising sediment transport.

All in all, climate change is the major reason for the drop of runoff and sediment transport of flood event in Gushanchuan watershed. During the period of human activity, i.e. from 1980 to 2010, the reduced number is $65.7 \%$ and $72.9 \%$ respectively.

\section{Conclusions}

(1) The year 1979 is the turning point of runoff and sediment transport in flood event of natural period and human activity impacting period in Gushanchuan basin, which analyzed by method of orderly clustering and MWP test.

(2) The model of runoff and sediment transport of flood event with the independent variable combined by mean areal precipitation and rainfall intensity is established using the data before the turning point year 1979.

(3) During the period of human activity, namely from 1980 to 2010, runoff of flood event in the basin decreased $1,771 \times 10^{4} \mathrm{~m}^{3}$, climate change and human activity occupies $65.7 \%$ and $34.3 \%$ respectively; sediment transport decreased $1,144 \times 10^{4} \mathrm{t}$, and the two percentage is $72.9 \%$ and $27.1 \%$.

\section{References:}

[1] Huang qiang, Zhao Xuehua, etc. The Analysis and Forecasting of Time Series of River Channel Runoff. Zhengzhou, Yellow River Conservancy Press, 2007. (in Chinese)

[2] A.N.Pettitt. A Non-Parametric Approach to the Change-Point Problem. Applied Statistics. Vol.28, No.2 (1979), 126-135.

[3] Sheng zhou, XieShiqian, Pan Yicheng. Probability Theory and Mathematical Statistics. Beijing: Higher Education Press, 1997. (in Chinese)

[4] JinShuangyan, Zhu Shitong, Zhang Zhiheng. Characteristics of Runoff and Sediment Transport of Floods in Huangfuchuan Basin. Hydrology. Vol.33, No.5 (2013), 88-92. (in Chinese)

[5] Chen Jianjun, JinShuangyan, Xu Jianhua. The Impacts of Climate Change and Human Activity on Runoff and Sediment Transportation of Flood Event in Gushanchuan Basin, Yellow River. Vol.29, No.5 (2009), 82-85. (in Chinese) 